\title{
Conceptualising and Measuring Student Disengagement in Higher Education: A Synthesis of the Literature
}

\author{
Lucy Chipchase ${ }^{1}$, Megan Davidson ${ }^{2}$, Felicity Blackstock ${ }^{1}$, Ros Bye $^{1}$, Peter Clothier ${ }^{1}$, Nerida Klupp ${ }^{1}$, Wendy \\ Nickson $^{2}$, Deborah Turner ${ }^{1} \&$ Mark Williams ${ }^{1}$ \\ ${ }^{1}$ School of Science and Health, Western Sydney University, Locked Bag 1797, Penrith, NSW 2751, Australia \\ ${ }^{2}$ Health Workforce Consulting \\ Correspondence: Dr LS Chipchase, School of Science and Health, Western Sydney University, Locked Bag 1797, \\ Penrith, NSW 2751, Australia
}

Received: February 9, 2017

Accepted: February 26, 2017

Online Published: March 2, 2017

doi:10.5430/ijhe.v6n2p31

URL: https://doi.org/10.5430/ijhe.v6n2p31

\begin{abstract}
Much has been written about why students engage in academic studies at university, with less attention given to the concept of disengagement. Understanding the risks and factors associated with student disengagement from learning provides opportunities for targeted remediation. The aims of this review were to (i) explore how student disengagement has been conceptualised, (ii) identify factors associated with disengagement, and (iii) identify measureable indicators of disengagement in previous literature. A systematic search was conducted across relevant databases and key websites. Reference lists of included papers were screened for additional publications. Studies and national published survey data were included if they addressed issues pertaining to student disengagement with learning or the academic environment, were in full text and in English. In the 32 papers that met the inclusion criteria, student disengagement was conceptualised as a multi-faceted, complex yet fluid state that has a combination of behavioural, emotional and cognitive domains influenced by intrinsic (psychological factors, low motivation, inadequate preparation for higher education, and unmet or unrealistic expectations) or extrinsic (competing demands, institutional structure and processes, teaching quality and online teaching and learning). A number of measurable indicators of disengagement were synthesised from the literature including those that were self-reported by students and those collected by a number of tertiary institutions. An examination of the conceptualisation, influences and indicators of disengagement could inform intervention programs to ameliorate the consequences of disengagement for students and academic institutions.
\end{abstract}

Keywords: Disengagement, Indicators, Influencing factors, Academic

\section{Introduction}

The concept of student engagement in learning and the academic environments has been explored extensively as a factor linked to learning, retention and academic success in higher education (Krause K.-L \& Armitage L., 2016) (Trowler V., 2016). A review of the literature in 2010 located over 1,000 academic papers devoted to student engagement (Trowler V., 2016). While much has been written, there remains variation in how student engagement is defined. One widely cited definition is "the time and effort students devote to activities that are empirically linked to desired outcomes of college and what institutions do to induce students to participate in these activities" (Kuh G D., 2009). Engagement has been considered by others to be more multidimensional with behavioural, emotional and cognitive constructs. For example, Hagel et al. (Hagel P, Carr R, Devlin M., 2012) suggest that behavioural constructs are the positive behaviours that students display towards academic, social, institutional and extra-curricular activities, while emotional constructs relate to the connection of students to their teachers, peers and institutions. Trowler (Trowler V., 2016) further develops this theory suggesting that these constructs could be positive, neutral or negative on a continuum. An example of positive engagement in the behavioural construct is attendance and participation, while negative engagement may involve boycotting or disrupting classes. Similarly, Krause (Kraus K-L., 2005) argued that, in addition to the generally positive meanings, engagement could be conceptualised negatively as a battle or conflict that some students experience within an unfamiliar, uninviting university culture. 
The complexity of the construct of engagement suggests that its antonym, disengagement, may also be a more complex concept than simply the absence of engagement behaviours, or the neutral to negative pole of an engagement continuum. Like engagement, disengagement is likely to not be a 'steady state' characteristic of students. The same student may display varying degrees of disengagement within a class, task, assignment, module, or across an entire course of study (Bryson C \& Hand L., 2007). For example, whilst a student is engaged with one unit of study they may be concurrently disengaged in another. Disengagement, whether ongoing or intermittent, obvious or subtle, may result in the student dropping out from units or a course of study, the accumulation of debt, or achieving lower grades with poorer employment prospects (Bennett J., 2007). For higher education institutes, this may result in loss of income and, if the problem is sufficiently large, have reputational impacts.

Early identification, particularly in the first year of study, of students who are disengaged or 'at risk' of disengagement could facilitate targeted interventions to improve outcomes for students (Nelson K J \& Creagh TA., 2013). This information will be useful to development and training practitioners of academia to develop targeted interventions. Strategies could include formalised programs such as learning and social support services to more individualised academic guidance and counselling. Thus, while many authors have sought to define student engagement, the aim of this review was to explore and synthesise the literature on student disengagement. Specifically, the review aimed to 1) determine how disengagement has been defined and conceptualised in the literature, 2) identify factors influencing disengagement and 3) identify measurable indicators of disengagement. This information is considered important to inform the design of effective programs for preventing, monitoring and remediating student disengagement from learning and the academic environment.

\section{Method}

A review was conducted by systematically searching literature from six databases including the Australian Education Index (AEI), Cumulative Index to Nursing and Allied Health Literature (CINAHL), Education Resources Information Centre (ERIC), Medline, PsychInfo and Proquest Education Journals using keywords with truncations. For example, the ERIC database search was disengage* AND ("tertiary student*" OR "university student*" OR "College student*" OR "higher education student*" OR "tertiary education" OR "university education" OR "college education" OR "higher education") limit to English. Phase one of the search was limited to English language peer-reviewed articles, published in academic journals between earliest dates available in each database to 15 July 2015 (Table 1). Phase two involved scanning relevant websites for recent reports on national student engagement surveys. The Australasian Survey of Student Engagement (AUSSE), the University Experience Survey and the First Year Experience Survey (FYES) were examined in Australia. In the USA and Canada, results of the National Survey of Student Engagement (NSSE) were examined, and in the UK, the Student Academic Experience Survey (SAES) and the UK Engagement Survey (UKES). The websites of the Centre for the Study of Higher Education at the University of Melbourne and the Higher Education Academy UK were also searched for relevant publications.

The yield of abstracts from database searches were exported into Endnote and duplicates deleted. One reviewer (MD) screened the titles and abstracts, and then excluded works that clearly did not meet the inclusion criteria (Table 1). The full text of remaining articles was obtained and screened for inclusion. Articles were verified as meeting the inclusion criteria by a second reviewer (WN). Doubts about the relevance of an article to the aims of the review were resolved through discussion. The reference lists of included articles were scanned and additional eligible articles added to the pool. From each article, data was extracted on bibliographic information, country, name of university or college, publication type, study type, student discipline/s, definition of engagement and disengagement, theoretical framework/s, indicators of disengagement, causes of disengagement, instruments used, software packages used for identification and monitoring, and potentially relevant articles in the reference list. The extracted data was then narratively synthesised to address the three aims of the review. 
Table 1. Inclusion and exclusion criteria

\begin{tabular}{|c|c|}
\hline Inclusion criteria & Exclusion criteria \\
\hline Full text & Abstracts \\
\hline English language & Letters \\
\hline Undergraduate students & Primary or secondary school students \\
\hline \multirow{7}{*}{$\begin{array}{l}\text { Addresses issues of higher education student } \\
\text { disengagement with learning/the academic } \\
\text { experience }\end{array}$} & Technical school students \\
\hline & Postgraduate students \\
\hline & 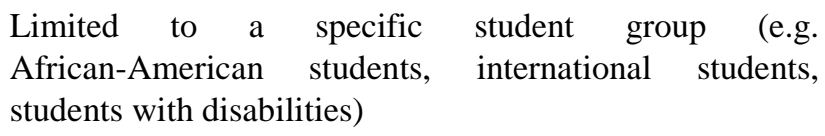 \\
\hline & Limited to a single subject/unit as described in the paper \\
\hline & Limited to online learning \\
\hline & Staff disengagement \\
\hline & Focus on classroom teaching techniques/ pedagogies \\
\hline
\end{tabular}

\section{Findings}

Of over 700 articles screened, 32 met the inclusion criteria and were included in the review. A broad range of aspects of student disengagement has been explored examining conceptualisation, factors influencing student disengagement and indicators of student disengagement. Papers were from five different countries (Australia $41 \%$, USA $31 \%$, UK $19 \%$, one each from Ireland, South Africa and one was not described), with 56\% of papers being peer reviewed journals and the remaining being from relevant websites. A range of study methods and data were described in the literature, with some studies using more than one method. Methods included student surveys (13 papers), student interviews ( 2 papers), narrative reviews (6 papers), theoretical framework conceptualisations (5 papers), opinion pieces (6 papers) and institutional data on student disengagement (2 papers).

\subsection{Conceptualisation of Student Disengagement}

As with the concept of engagement, disengagement has been viewed from a simple concept of what students do not do, through to more nuanced and complex conceptualisations. Four conceptualisations of student disengagement were identified through this review.

\subsubsection{Disengagement as a Character Fault}

Disengagement has been considered a character fault inherent in disengaged students. Trout (Trout PA., 1997) used adjectives such as disaffected, detached, indifferent, alienated, resentful and hostile to describe students who are disengaged. Students' disengaged behaviours (for example, not doing assigned reading or class preparation, not attending or participating in class discussion) were viewed as arising from their negative attitudes to academic pursuits. Disengaged students were characterised as resenting course demands, being impatient and bored with intellectual pursuits.

Furthering this work, another writer from the 1990s (Marchese T., 1998) viewed disengagement as generational, noting that students of this time were "a 1990s generation described as consumerist, uncivil, demanding, preoccupied with work and as caring more for GPAs (grade point averages) and degrees than the life of the mind". Kazmi (Kazmi A., 2010) adopted a softer and more passive characterisation by deeming disengagement to reflect "unawareness" rather than "laziness" using sleepwalking as a metaphor to describe the disengaged student, likening their state to one of unconsciousness or auto pilot. However, the conceptualisation of disengagement as a character fault has been criticised by others. Hockings et al. (Hockings C, Cooke S, Yamashita H, McGinty S, Bowl M., 2008) warn against judging students who "appear to be disengaged as inferior, deficient or problematic" and point out that the concept of disengagement is complex, and not a stable trait within students who may be differently engaged over time or between tasks and subjects.

\subsubsection{Disengagement as Non-engagement, Non-participation}

Engagement has been defined as the time and effort that students devote to educationally-purposeful activities, or more broadly as students' interactions with their learning activities, their academic institutions (e.g. the university) 
and each other, Thus, the antonym, disengagement, has been conceptualised as not engaging, participating or interacting in learning activities, and not engaging with the institution or their peers. Disengagement from the 'institution' can range from a lack of involvement in their academic studies to disengagement from social activities such as participating in clubs, committees and social events. Disengaged students have been described by what they do not do, such as not preparing for class, reading set material, participating in class, completing assignments or taking advantage of learning opportunities (Baron P \& Corbin L., 2012) (Brint S \& Cantwell AM., 2010) (Flacks R, Thomson G, Douglass J, Caspary K., 2004) (Larkin D \& Harrison I., 2011) (Nelson K J, Quinn C, Marringron A, Clarke JA., 2012).

Krause (Kraus K-L., 2005) proposed that alternatives to engagement were "inertia, apathy, disillusionment or engagement in other pursuits". This author held the position that inertia was a more useful term than disengagement as "the latter suggests an active detachment or separation, whereas the former is more suggestive of doing nothing, which aptly depicts the state of being for the group of students who do not actively pursue opportunities to engage in their learning community" (Kraus K-L., 2005). Krause (Kraus K-L., 2005) also observed that "inertia is also signified by failure to self-regulate and motivate oneself".

However, disengagement from academic and social activities does not necessarily co-occur. That is, students may be academically disengaged but remain socially engaged with the institution (Brint S \& Cantwell AM., 2014), or vice-versa. The concept of non-participation as engagement has therefore also been criticised. Harper and Quaye (Harper SR, \& Quaye SJ., 2009) stated that "engagement is more than involvement or participation, it requires feelings and sense-making as well as activity". Therefore, under the approach proposed by Harper and Quaye (Harper SR, \& Quaye SJ., 2009), non-participation from academic studies should not be viewed as disengagement unless the student has also disengaged emotionally and behaviourally.

\subsubsection{Disengagement as a Multidimensional Construct}

The three domains identified as making up engagement (behavioural, emotional and cognitive) have also been applied to disengagement, suggesting it is a multi-dimensional construct (Trowler V., 2016). This was expanded upon by Brint and Cantwell (Brint S \& Cantwell AM., 2014) who proposed five dimensions of disengagement based on students' values, motivations, study behaviours, academic interactions and competing involvements, where disengagement may occur in one or more dimensions. Values disengagement occurs where students do not value education, for whom study is a low priority, or who see study only in terms of gaining a qualification. Motivation disengagement occurs where students are not motivated to achieve educational goals while behavioural disengagement is observed through limited time spent on study, class non-attendance and non-completion of assignments. Interactional disengagement occurs where students do not interact with their teachers or peers and competing involvements are non-academic pursuits, from entertainment and social activities to paid employment. Students whose time and energies are spent on non-academic activities were thought to have reduced opportunity and motivation for academic engagement (Brint S \& Cantwell AM., 2014).

Trowler (Trowler V., 2016), proposed that disengagement could be described as 'non-engagement', occupying the neutral part of the engagement continuum between positive and negative engagement poles. Examples of non-engagement in the behavioural, emotional and cognitive domains were said to be non-attendance, boredom and assignments that were "late, rushed or absent" respectively. Non-engagement was also described by Trowler (Trowler V., 2016) as withdrawal or apathy. The negative pole, termed negative engagement, was proposed to be evidenced behaviourally by boycotting, picketing, disruption of learning activities, emotionally by rejection of learning and cognitively by redefinition the parameters of assignments (cognitive dimensions) (Trowler V., 2016). Trowler (Trowler V., 2016) also suggested that it would be possible for a student to be positively engaged in one or more dimensions with one aspect of their studies while negatively engaged in other aspects. Trowler (Trowler V., 2016) provides the example of a feminist student who "attends all lectures and complies positively with all behavioural engagement norms, while engaging cognitively in a negative fashion by rejecting a 'phallocentric' social science and submitting assignments on a topic she defined according to her own epistemology".

\subsubsection{Disengagement as Alienation}

With a more philosophical approach, Mann (Mann SJ., 2001) conceptualised disengagement as alienation, citing the Oxford English Dictionary definition of "the state or experience of being isolated from a group or an activity to which one should belong or in which one should be involved". She observed that the features of surface learners (rote learning, memorisation and reproduction, lack of reflection, preoccupation with task completion) and strategic learners (focus on assessment requirements and lecturer expectations, careful management of time and effort, aim of achieving high grades) both resulted in "an alienation from the subject and process of study" (Mann SJ., 2001). The 
first type of learning is passive while the second, active. However, both locate "control for their engagement in the perceived demands and criteria for success of external others" (Mann SJ., 2001). Mann (Mann SJ., 2001) identified seven philosophical perspectives on alienation (drawn, for example, from the works of Lyotard (Lyotard J.-F., 1984), Lacan (Lacan J., 1998) and Foucault (Foucault M., 1972) (Foucault, M., 1979) to explore the student experience of alienation in higher education. The seven perspectives view the experience of alienation from learning as: 1) a postmodern condition driven by sociocultural context, 2) being positioned as being subject/object and the student's entry into a pre-existing discourse, 3) the student as an outsider, 4) a state of being bereft of the capacity for creativity, 5) a sense of loss of ownership of the learning process, 6) being disciplined into docility through assessment practices, and 7) alienation as a strategy for self-preservation.

Case's theoretical framework on alienation and engagement (Case JM., 2008) developed Mann's work and proposed a new and useful addition to perspectives in student disengagement research. The framework organises Mann's seven perspectives into three categories of student experience in the higher education community as "entering" (students' reasons for participation), "fitting in" (students' experiences of access and entry) and "staying" (students' experiences of power relationships in the assessment process).

\subsubsection{A Definition of Disengagement}

Based on the literature synthesis, academic disengagement can be defined as a multi-faceted, complex yet fluid state, which has a combination of behavioural, emotional and cognitive domains.

\subsection{Factors Influencing Disengagement}

A number of factors, both intrinsic and extrinsic to the student were identified as influencing disengagement. Intrinsic factors were psychological issues, low motivation, inadequate preparation for tertiary study and unmet/unrealistic expectations. Extrinsic factors were competing demands/financial stress, institutional structures and processes, academic staff factors and online teaching and learning. Each of these factors will be described separately although it is likely that some moderate others.

\subsubsection{Psychological Factors}

Emotional health and psychological distress were reasons students frequently provided for considering withdrawal from study (Baik C, Naylor R, Arkoudis S., 2015), with the incidence of psychological distress considerably higher amongst university students than the general population (Baik C, Naylor R, Arkoudis S., 2015). Stress was often associated with managing the workload of university, balancing study while working along with financial worries. Psychological issues were also raised by Mann(Mann SJ., 2001) who proposed that for some students "Learning has the potential to trouble, to offer a glimpse into chaos and disorder and into the unknown", suggesting that disengagement may be a self-preservation strategy for dealing with the psychological distress.

\subsubsection{Low Motivation}

A connection between a lack of motivation to learn or achieve academic goals has been posited by a number of authors to result in students' disengagement from learning activities and the academic experience more generally (Kraus K-L., 2005) (Hunter-Jones P., 2012) (Pace RC., 1990). Krause (Kraus K-L., 2005) viewed lack of motivation as providing potential for "inertia to deteriorate into despondency and disengagement". In a continuum of learner disengagement, one of the characteristics of the "ambivalent learner" was identified as "motivational issues" (Hunter-Jones P., 2012). The link between motivation and disengagement is supported by an analysis of a large dataset from the College Experience Questionnaire with low grades explained by "low motivation for academic achievement and academic goals" (Pace RC., 1990). Further, the 2015 report of the NSSE suggested that sufficient challenge in academic work, and support for learning were needed for student motivation so that learners could "reach their potential" (National Survey of Student Engagement, 2015). However, only 54\% of first year and 61\% of senior students said they were sufficiently challenged "to do your best work". Low motivation is thought to be due to many factors including, inter alia, pressure from parents and peers to attend university, not being in the course of choice, uncertainty about future goals, a lack of alternatives to university and high youth unemployment rates (Baik C, Naylor R, Arkoudis S., 2015).

\subsubsection{Preparation for Study and Academic Capacity}

A number of authors identified that students may not be adequately prepared for higher or tertiary education, leading to disengagement. Learning at a tertiary level requires a different approach, with students having to adapt to a less structured, less monitored and less individually supported learning environment that requires greater self-motivation. Students who enrol in college or university, straight from high school, find it challenging to transition their learning 
from being "told what they need to know" at school, to "one where they must direct their own learning" at university (Baldwin A \& Koh E., 2012). Passive and surface learning approaches that may be successful at high school, are thought to not result in high grades at university. In contrast, active and deep learning approaches are generally required for successful university studies, and are reportedly not naturally inherent for first year students (Baldwin A \& Koh E., 2012). The 2014 Australian FYES found that only 50\% of students agreed that "My final school year was a very good preparation for the study I am now doing" (Baik C, Naylor R, Arkoudis S., 2015). Survey data and focus groups identified an incompatibility between the expected learning styles of first year students and those of the university educators, which was considered to be the main factor associated with student disengagement (Baldwin A \& Koh E., 2012). Further, the 2015 NSSE results highlight that students who did not study much in high school (five or fewer hours per week) tended to carry these habits into first year of college (National Survey of Student Engagement, 2015).

Academic capacity may also influence student disengagement, with Australian data suggesting that first year students with lower university entry scores are more likely to not be enrolled the following year (Baldwin A \& Koh E., 2012). This was exemplified by Kemp and Norton (Kemp D, \& Norton A., 2014) who reported that 50\% of students with entry scores less than 60 (out of 100) were unlikely to complete their degree in six years and one quarter of students with entry scores below 50 were not at any higher education provider the following year. In contrast, students who entered with higher entry scores had an attrition rate that declined every year over a five-year period (2007-2011).

\subsubsection{Unmet or Unrealistic Expectations}

Students who have unmet or unrealistic expectations about university may become disengaged, unless they can modify their expectations in light of their first year experience. Student surveys identified unrealistic expectations about the standard of work expected at university (Baik C, Naylor R, Arkoudis S., 2015), anticipated grades (Baik C, Naylor R, Arkoudis S., 2015) (National Survey of Student Engagement, 2015) and the amount of work required (Larkin D \& Harrison I., 2011) (Baik C, Naylor R, Arkoudis S., 2015) (Soilemetzidis I, Bennett P, Buckley A, Hillman N, Stoakes G., 2014). In the 2014 UK Student Academic Experience Survey (Soilemetzidis I, Bennett P, Buckley A, Hillman N, Stoakes G., 2014), 12\% of students said their university experience was "worse than expected". This was comparable to the $18 \%$ of commencing students in Australia who said their first year university experience had not lived up to their expectations (Baik C, Naylor R, Arkoudis S., 2015). Unmet expectations were reported by $25 \%$ of Australian students considering early departure from higher education, highlighting the potential impact of expectations on disengagement.

\subsubsection{Competing Demands and Financial Stress}

A number of authors have observed that excessive time in paid work and other competing non-academic pursuits impact negatively on academic engagement and achievement (Kraus K-L., 2005) (Baron P \& Corbin L., 2012) (Brint S \& Cantwell AM., 2014) (McInnis C., 2001) (Salamonson Y, Andrew S, Everett B., 2009). Common reasons students have self-reported considering deferring or withdrawing from a course are financial stress, paid work commitments, workload, study/life balance and family responsibilities (Baik C, Naylor R, Arkoudis S., 2015) (National Survey of Student Engagement, 2015). Students who spend too much time on paid work and other activities, have less time available for study, and students who worry about money find it difficult to concentrate on study (Baik C, Naylor R, Arkoudis S., 2015) (National Survey of Student Engagement, 2015). For some students competing activities, including socialising, entertainment and the Internet, may also be prioritised over study, suggesting that while many students work to meet basic living expenses, many are likely to be working to afford extras (Brint S \& Cantwell AM., 2014). An emerging concern is the extent to which students are distracted from learning by the use of social media (National Survey of Student Engagement, 2015) (National Survey of Student Engagement, 2014).

\subsubsection{Institutional Structures and Processes}

Some authors propose that university structures and processes unintentionally facilitate disengagement ()$($ Kraus K-L., 2005) (Baron P \& Corbin L., 2012) (Hu S \& Kuh GD., 2002). Organisational culture and processes can be alienating, difficult to understand and negotiate. This is thought particularly true for international students, those first in family to attend university or from a background of socioeconomic disadvantage (Kraus K-L., 2005). Brint and Cantwell (Brint S \& Cantwell AM., 2014) observed that "any hierarchical system is bound to create disengaged populations among those who have failed to succeed on the institution's terms". In a study of over 50,000 American student responses to the College Students Experiences Questionnaire, Hu and Kuh (Hu S \& Kuh GD., 2002) found that students were less likely to be categorised as disengaged if they "perceived that their institution emphasized 
scholarship and intellectual and critical analysis, had high quality personal relations between groups, and emphasized vocational and practical matters".

Baron and Corbin (Baron P \& Corbin L., 2012) identified a number of trends in the Australian context with the potential to contribute to student disengagement: larger class sizes, reduced staff/student ratios and fewer contact hours. These can be seen to be a result, at least partly, of changes in funding for higher education and the 'commodification' of higher education. Baron and Corbin (Baron P \& Corbin L., 2012) also suggested that the move from compulsory to voluntary student union membership, observed in Australia, resulted in a reduction in opportunities for students to be engaged in non-academic activities. Baron and Corbin (Baron P \& Corbin L., 2012) also noted that institutional responses to changing student expectations, such as online learning and accelerated course options, together with centralisation of services may ironically decrease student satisfaction and "contribute to students' sense of anonymity and disengagement" (Baron P \& Corbin L., 2012).

Universities have tried to implement activities to foster engagement. However, in some situations these appear to have negative or limited effect on engagement. For example, orientation programs for commencing students that aim to engage students with the university community and prepare them for their course have been found to be less than optimal, with poor attendance rates (only $30 \%$ of people reporting to engage with orientation activities) and fewer than half of students (42\%) believing the programs helped them get off to a good start (Baik C, Naylor R, Arkoudis S., 2015). Inadequate or untimely student support services has also been thought to contribute to student disengagement (Baik C, Naylor R, Arkoudis S., 2015).

\subsubsection{Academic Staff Factors}

The actions, attitudes and behaviours of teaching staff may facilitate student disengagement; content that is inaccessible and the use of didactic and static pedagogies by teachers who are unskilled or uncomfortable with new technologies or methods, moderates student disengagement (Osterholt DA \& Barratt K., 2016). Student perceptions of teachers as unapproachable or lacking in enthusiasm for the subject or concern for students and their learning can drive disengagement, as can a lack of consistency in the information, messages and assessment in teaching teams (Bryson C \& Hand L., 2007).

\subsubsection{Online Teaching and Learning}

The growth in the use of flexible online learning technologies appears to be contributing to disengagement because it reduces the amount of time students spend on campus or interacting face-to-face with other students and staff. Evidence that online learning reduces academic engagement comes from the 2014 Australian FYES in which 35\% of students said they never participated in online discussion groups compared to $19 \%$ for face-to-face learning (Baik C, Naylor R, Arkoudis S., 2015). Teacher moderation (for example, moderation of the use of discussion boards) in online discussions appears to be important to prevent disengagement of some students in the online learning community (Krause K.-L \& Armitage L., 2016).

\subsection{Indicators of Academic Disengagement}

In the reviewed literature, indicators of student academic disengagement could be categorised into eleven target areas, with measurable indicators for each area (Table 2). The indicators identified are limited to indicators of academic disengagement that could be measured in the first year at university. While these indicators were deemed relevant and measurable in first year cohorts, they are also relevant and measurable to all cohorts and will also identify students for whom disengagement may occur later in their program of study. When an indicator was cited in general terms such as "poor attendance" but without a specific cut-off point that would classify an individual student as a poor attender, it was not included. Self-reported indicators of disengagement were derived from items in student surveys. Survey items that could not distinguish between lack of opportunity and student disengagement were not included. For example, survey items evaluating frequency of "making class presentations" or "working with other students on projects during a class" were not considered to be indicators. Other survey questions that may indicate a lack of need rather than disengagement, such as 'I regularly seek the advice and assistance of the teaching staff' were also excluded from the synthesis. Composites of items from surveys (e.g. scales formed by NSSE items) and indicators that refer to completion of a university-specific program are also not presented. 
Table 2. Indicators of student disengagement

\begin{tabular}{|c|c|}
\hline Target & Indicator \\
\hline Attendance & $\begin{array}{l}\text { Fails to attend first class } \\
\text { Not attending required classes by Week 3, or other key } \\
\text { classes later in the semester } \\
\text { Less than } 80 \% \text { lecture attendance } \\
\text { Consistent poor attendance at classes }\end{array}$ \\
\hline Preparation for classes & $\begin{array}{l}\text { Does not access subject outline } \\
\text { Comes to class without completing readings or } \\
\text { assignments } \\
\text { Does not prepare for class e.g. does complete note } \\
\text { reading }\end{array}$ \\
\hline Participation & $\begin{array}{l}\text { Enrolled without unit activity } \\
\text { Does not contribute to class discussion } \\
\text { Does not participate in discussions online or face-to-face } \\
\text { Does not contribute to course discussions in other ways }\end{array}$ \\
\hline Time spent studying & $\begin{array}{l}\text { Does not keep up to date with studies } \\
\text { Spends less than } 9 \text { hours per week on individual study } \\
\text { Spends less than } 18 \text { hours on total study time per week }\end{array}$ \\
\hline Effort spent studying & $\begin{array}{l}\text { Does not work hard to master difficult content } \\
\text { Does not prepare two or more drafts of an assignment } \\
\text { before handing it in } \\
\text { Does not use student support learning support services } \\
\text { Does not work harder than they think they can to meet a } \\
\text { teacher's/tutor's standards or expectations } \\
\text { Does not review notes after class }\end{array}$ \\
\hline $\begin{array}{l}\text { Access online } \\
\text { Learning Management System (LMS) }\end{array}$ & $\begin{array}{l}\text { Does not access subject information. } \\
\text { Does not access LMS } \\
\text { Low or very high levels of on-line activity }\end{array}$ \\
\hline Assessment & $\begin{array}{l}\text { Does not submit first major assignment or late } \\
\text { submission or fails major assignment } \\
\text { Failure to submit or failure in progressive assessment } \\
\text { items }\end{array}$ \\
\hline Academic performance & $\begin{array}{l}\text { Fails or is repeating a subject } \\
\text { Grade point average of less than four out of seven in first } \\
\text { two semesters } \\
\text { Meets criteria for 'on probation' } \\
\text { Receives a notice that they are at risk of exclusion }\end{array}$ \\
\hline Interaction with teachers & Does not seek advice from academic staff \\
\hline Collaborative study & Does not work/collaborate with other students \\
\hline Enjoyment/satisfaction with academic study & Is not satisfied with study \\
\hline
\end{tabular}




\section{Discussion}

This review is the first to explore and synthesise the literature on student disengagement, providing an analysis of the conceptualisation of disengagement as well as identification of factors influencing, and indicators of student disengagement. Two prior reviews of the literature (Krause K.-L \& Armitage L., 2016) (Trowler V., 2016) focussed on student engagement rather than disengagement. Although the two are fundamentally related, the current review provides additional insights for universities and programs to examine how they might ameliorate the problem of student academic disengagement, which can have serious consequences for individuals and for the higher education organisation.

While no specific definitions of disengagement were located by this review, generally disengagement has been described as ranging from a character fault through to alienation and non-engagement. These descriptions tend to view the student as the issue. Being bored as a result of full and imaginative teaching is not a character fault for students. Students may respond in a negative way to the university experience, often as a consequence of poor advice in course selection, poor course organisation or mediocre teaching. Opting out of a course is therefore a perfectly rational response when expectations are not made. Therefore, based on an amalgamation of all previous work, disengagement can be defined as a multi-faceted, complex yet fluid state, that has a combination of behavioural, emotional and cognitive domains, that is influenced by intrinsic (low motivation, inadequate preparation for university) and extrinsic factors (e.g. the institution's structures and processes, teaching quality).

Most universities use a range of generic strategies to engage all commencing students, such as career advice, orientation activities, and learning and social support services to help students make the transition to university. Many have also developed specific programs to aid early identification of students at risk of disengagement (Nelson K J \& Creagh TA., 2013) (National Survey of Student Engagement, 2014). Generic engagement programs and programs targeting cohorts of students thought to be at risk (for example, those with low entry scores) are prevention style programs. That means that recruitment to the program is not based on students being identified as disengaged at the time. Rather, these programs aim to minimise or prevent students becoming disengaged and are based around the literature examining factors influencing engagement. On the other hand, targeted interventions to provide remediation to students identified as disengaged can be viewed as intervention programs.

Universities have invested substantial resources over the last twenty years into the development of prevention and intervention programs for minimising the risk and/or addressing student disengagement. However, evaluation of these programs suggests that they may not always be having the desired or anticipated impact. For example, only $30 \%$ of people report engaging with orientation activities, fewer than half believe that the programs helped them get off to a good start (Baik C, Naylor R, Arkoudis S., 2015) and student attrition rates remaining stable at best. Further complicating the complex nature of student disengagement is the rapid change in how learning opportunities are provided in the higher education sector. The percentage of online study has increased, with online enrolments increasing at rates in excess of those overall in higher education (Allen IE \& Seaman J., 2016). In 2002, less than half of higher education institutes offered online learning, and this has increased to $70 \%$ in the last decade (Allen IE \& Seaman J., 2016). Further, over $30 \%$ of tertiary students in the United States complete at least one unit in an online learning environment (Allen IE \& Seaman J., 2016). These figures are representative of fully online learning and do not include the percentage of students engaged in a blended format of online and face-to-face learning activities, which is likely to substantially increase these numbers. There has also been proliferation of multi-campus course delivery (both national campus and international campus) as universities expand to meet regional/rural/remote learners' needs, and flexibility of delivery to meet the diverse approaches to learning has also been embraced.

Presently, higher education institutes are limited in their capacity for targeted intervention to address student disengagement, as there is no valid and reliable mechanism for identifying students at risk of disengagement. Student surveys, which are typically conducted in the latter part of the first year of study, and institutional data collected from departing students, are readily available to inform prevention programs, but these do not allow for diagnosis of individual disengagement nor targeted interventions for specific students. From the literature reviewed, a range of measurable indicators of student disengagement were identified in the domains of attendance, preparation for and participation in classes, time spent studying, effort expended, accessing LMS, assessment, academic performance, interaction with teachers, collaborative study, and enjoyment/ satisfaction with academic study. Most of these indicators are in the behavioural and cognitive domains of disengagement, with only enjoyment/satisfaction in the emotional domain. These indicators can be categorised as self-reported, or can be captured by an institution from academic records or online LMS. This information provides a foundation for the formulation of a screening tool to assess student disengagement. The process of using indicators to identify students is analogous to a diagnostic test 
process. Universities and programs need to have available screening tools using selected indicators that will flag students at risk of disengaging with a reasonable degree of accuracy. Such tools or processes provide the potential to then offer interventions addressing the identified underlying indicators and factors influencing the student's disengagement. The identification process could also enhance the capacity to individually tailor interventions, rather than the usual one-size-fits-all approach of many current disengagement prevention programs. A diagnostic tool would act similarly to a learning needs assessment, suggesting focussed areas for provision of support.

The design of preventative and intervention programs should be informed by "best practice' principles, such as "Ten working principles for enhancing student engagement" (Kraus K-L., 2005), "High-impact educational practices" (Kuh GD., 2008) and "Social justice principles" (Nelson K J \& Creagh TA., 2013). The major reasons students consider withdrawal from study warrant the greatest attention as efforts targeting these causes may potentially yield the greatest benefit for students, universities and the community at large. Baron and Corbin (Baron P \& Corbin L., 2012) argue that a holistic approach is needed from universities, including "listening carefully to diverse student voices, particularly the voices of the disengaged" and "to the voices of academic and administrative staff, who are often at the front line of student engagement issues. Understanding students' perspectives on their learning and personal growth is important and failure to do so may lead to ineffective teaching and learning (Osterholt DA \& Barratt K., 2016). This review provides the foundation for further work to be conducted establishing methods for identifying disengaged students and clarity to factors to consider in designing interventions utilising the students' perspective as well as the academic perspective that has been previously regarded.

In addition to direct preventative and intervention programs, universities should consider their potential to influence governmental policies on financial support for students. Reform of financial support to studying students may lead to a decrease in the influence of competing demands such as work to support oneself. In light of the burgeoning debt associated with public funded education provision, particularly in Australia, targeted financial support through schemes such as Youth Allowance, or increasing access to scholarships for study may positively influence engagement rates. The net result may be lower costs to the community as students successfully complete their higher education studies in shorter timeframes, and with fewer academic failures and debt accumulation.

While the review focussed on the relatively small body of literature that explicitly considered the issue of disengagement, works in the much larger body of literature focussed on engagement may nevertheless have contained aspects related to disengagement. Identification of indicators was limited to only those deemed measurable, and this may limit our capacity to generate a valid tool to identify students who are disengaged or 'at risk of' disengagement. By excluding indicators that do not currently have a reliable and valid measurement tool, we may have omitted an indicator that demonstrates disengagement. Further research to design valid and reliable measures of indicators is required.

\section{Conclusion}

This paper provides a new definition of disengagement and highlights factors that influence disengagement. In addition, the synthesis of the literature provides a list of measurable indicators of disengagement, some that were self-reported by students and others collected by tertiary institutions. Disengagement is defined as a complex construct that is a multi-dimensional fluid state, with behavioural, emotional and cognitive domains and is influenced by both intrinsic and extrinsic factors. The design of disengagement prevention and intervention programs should be informed by the intrinsic and extrinsic causes identified and by best practice principles. Capacity to identify students who are likely to disengage, based on either extrinsic or intrinsic factors, with a valid and reliable tool based on the indicators identified in this review may allow for more targeted remediation. Further research should examine the development of such a tool. Individualised identification of student disengagement may also focus interventions to meet the needs of students yielding improved outcomes, as opposed to the current general programs offered by higher education providers.

\section{Acknowledgments}

This work was funded by a Catalysing Innovation in Learning and Teaching grant from the School of Science and Health, Western Sydney University.

\section{Competing Interests}

The authors declare that they have no competing interests. 


\section{References}

Allen IE \& Seaman J. (2016). Changing course: ten years of tracking online education in the United States. [cited 2016 June 2]. Avialble from: http://www.onlinelearningsurvey.com/reports/changingcourse.pdf

Baik C, Naylor R, Arkoudis S. (2015). The first year experience in Australian universities: Findings from two decades, 1994-2014. Melbourne, Australia: Melbourne Centre for the Study of Higher Education, The University of Melbourne.

Baldwin A \& Koh E. (2012). Enhancing student engagement in large, non-disciplinary first year survey courses. International Journal of Teaching and Learning in Higher Education, 24(1), 113-121.

Baron P \& Corbin L. (2012). Student engagement: rhetoric and reality. Higher Education Research and Development, 31(6), 759-772. https://doi.org/10.1080/07294360.2012.655711

Bennett J. (2007). Work-based learning and social support: Relative influences on high school seniors' occupational engagement orientations. Career and Technical Education Research, 32(2), 187-214. https://doi.org/10.1177/0894845314543496

Brint S \& Cantwell AM. (2014). Conceptualizing, measuring, and analyzing the characteristics of academically disengaged students: results from UCUES 2010. Journal of College Student Development, 55(8), 808-823. https://doi.org/10.1353/csd.2014.0080

Bryson C \& Hand L. (2007). The role of engagement in inspiring teaching and learning. Innovations in Education and Teaching International, 44(4), 349-362. https://doi.org/10.1080/14703290701602748

Case JM. (2008). Alienation and engagement: development of an alternative theoretical framework for understanding student learning. Higher Education, 55, 321-332. https://doi.org/10.1007/s10734-007-9057-5

Department of Education. Completion rates of domestic bachelor students: a cohort analysis, 2005-2013. Canberra, ACT: Department of Education.

Flacks R, Thomson G, Douglass J, Caspary K. (2004). Learning and academic engagement in the multiversity: student experience in the research university-21st century (seru21) project - results of the first university of california undergraduate experience survey (pp. 39): Center for Studies in Higher Education. University of California, Berkeley, 771 Evans Hall \#4650, Berkeley, CA 94720-4650.

Foucault M. (1972). The Archaeology of Knowledge. London: Tavistock.

Foucault, M. (1979). Discipline and Punish: The Birth of the Prison. Harmondsworth: Penguin.

Hagel P, Carr R, Devlin M. (2012). Conceptualising and measuring student engagement through the Australasian Survey of Student Engagement (AUSSE): A critique. assessment and evaluation. Higher Education, 37(4), 475-486. https://doi.org/10.1080/02602938.2010.545870

Harper SR, \& Quaye SJ. (2009). Beyond sameness, with engagement and outcomes for all. in: student engagement in higher education. New York and London: Routledge.

Hockings C, Cooke S, Yamashita H, McGinty S, Bowl M. (2008). Switched off? A study of disengagement among computing students at two universities. Research Papers in Education, 23(2), 191-201. https://doi.org/10.1080/02671520802048729

Hu S \& Kuh GD. (2002). Being (dis)engaged in educationally purposeful activities: the influences of student and institutional characteristics. Research in Higher Education, 43(5), 555-575. https://doi.org/10.1023/A:1020114231387

Hunter-Jones P. (2012). The continuum of learner disengagement: ethnographic insights into experiential learning in marketing education. Journal of Marketing Education, 34(1), 19-29. https://doi.org/10.1177/0273475311430801

Kazmi A. (2010). Sleepwalking through undergrad: using student engagement as an institutional alarm clock. College Quarterly, 13(1), 15.

Kemp D, \& Norton A. (2014). Review of the demand driven funding system report.: Department of Education and Training. [cited 2016, June 2]. Available from: https://docs.education.gov.au/node/35537.

Kraus K-L. (2005). Understanding and promoting student engagement in university learning communities. Paper presented as keynote address: Engaged, inert or otherwise occupied?: Deconstructing the 21st century 
undergradsuate student Procedings of the James Cook University Symposium 2005, Sharing Scholarship in Learning and Teaching: Engaging students. James Cook University, Townsville/Cairns, Queensland: Centre for the Study of Higher Education.

Krause K.-L \& Armitage L. (2016). Australian student engagement, belonging, retention and success: a synthesis of the literature. [cited 2016 Jun 1]. Available from https://www.heacademy.ac.uk

Kuh GD. (2008). High-impact educational practices: What they are, who has access to them, and why they matter. Washington, DC: Association of American Colleges and Universities; 2014.

Kuh G D. (2009). What student affairs professionals need to know about student engagement. Journal of College Student Development, 50(6), 683-706. https://doi.org/10.1353/csd.0.0099

Lacan J. (1998). The seminar of jaques lacan, book $i$ : freud's papers on technique 1953-1954. Cambridge, Cambridge University Press.

Larkin D \& Harrison I. (2011). Exploring student engagement through the use of diaries. Psychology Teaching Review, 17(1), 64-77.

Lyotard J.-F. (1984). The postmodern condition: a report on knowledge theory and history of literature. Manchester: Manchester University Press.

Mann SJ. (2001). Alternative perspectives on the student experience: alienation and engagement. Studies in Higher Education, 26(1), 7-19. https://doi.org/10.1080/03075070020030689

Marchese T. (1998). Disengaged students. Change, 3(1), 4. https://doi.org/10.1080/00091389809602599

McInnis C. (2001). Signs of disengagement? the changing undergraduate experience in australian universities. Inaugural Professorial Lecture, 16.

National Survey of Student Engagement. (2014). Bringing the Institution into Focus - Annual Results 2014. Bloomington, In: Indiana University Center for Postsecondary Research.

National Survey of Student Engagement. (2015). Engagement insights. Survey findings on the quality of undergraduate education: Bloomington, Indiana: Indiana University Center for Postsecondary Research.

Nelson K J \& Creagh TA. (2013). A good practice guide: Safeguarding student learning engagement. Brisbane, Australia: Queensland University of Technology.

Nelson K J, Quinn C, Marringron A, Clarke JA. (2012). Good practice for enhancing the engagement and success of commencing students. Higher Education, 63, 83-96. https://doi.org/10.1007/s10734-011-9426-y

Osterholt DA \& Barratt K. (2016). Breaking the Teaching and Learning Gridlock. New England Journal of Higher Education. [cited 2016, jun 1] Available from: http://www.nebhe.org/thejournal/breaking-the-teaching-and-learning-gridlock/.

Pace RC. (1990). The undergraduates: a report of their activities and progress in college in the 1980's. Los Angeles, California, Center for the Study of Evaluation University of California.

Parliamentary Budget Office. (2016). Higher education loan programme. [Cited 2016 June 2]. Available from: http://www.aph.gov.au/About_Parliament/Parliamentary_Departments/Parliamentary_Budget_Office/research_ reports/Higher_Education_Loan_Programme

Salamonson Y, Andrew S, Everett B. (2009). Academic engagement and disengagement as predictors of performance in pathophysiology among nursing students. Contemporary Nurse, 32(1-2), 123-132. https://doi.org/10.5172/conu.32.1-2.123

Soilemetzidis I, Bennett P, Buckley A, Hillman N, Stoakes G. (2014). The HEPI-HEA Student Academic Experience Survey 2014. UK: Higher Education Policy Institute and The Higher Education Academy.

Trout PA. (1997). Disengaged students and the decline of academic standards. Academic Questions, 10(2), 46-56. https://doi.org/10.1007/s12129-997-1067-3

Trowler V. (2016). Student engagement literature review. [cited 2016 June 1]. Available from: https://www.heacademy.ac.uk/system/files/studentengagementliteraturereview_1.pdf

UES-Consortium. (2014). University Experience Survey National Report. [Cited 2016 Jul 1]. Available from https://www.qilt.edu.au/docs/default-source/ues-national-report/2014-university-experience-survey-national-rep ort/ues14_report_final_access2a.pdf?sfvrsn=4. 